\title{
Histerectomia: aspectos psicossociais e processos de enfrentamento
}

\author{
Lúcia Robertta Matos Silva dos Santos' - Universidade Federal da Paraíba, João Pessoa, Brasil \\ Ana Alayde Werba Saldanha - Universidade Federal da Paraíba, João Pessoa, Brasil
}

\begin{abstract}
Resumo
O objetivo deste estudo foi investigar os aspectos psicossociais e as construções de enfrentamento da cirurgia de histerectomia. Tratou-se de estudo de coorte, longitudinal, envolvendo 10 mulheres, com média de idade de 44 anos, baixa escolaridade e renda, atendidas em um hospital municipal do Estado da Paraíba. Utilizou-se a Escala de Modo de Enfrentamento de Problemas (EMEP) e entrevistas semiestruturadas realizados na maternidade e nas residências, no intervalo entre o pré-cirúrgico e no sexto mês do pós-operatório. Para análise dos resultados, utilizou-se estatística descritiva e bivariada e a técnica de análise de conteúdo. Os resultados indicaram a variabilidade das estratégias de enfrentamento, com predomínio na busca de práticas religiosas, seguido de focado no problema. Os discursos evidenciam receio pela perda da feminilidade e mobilização de sentimentos de temor quanto à cirurgia. Os resultados fornecem subsídios para a intervenção psicológica, enfatizando processos de comunicação mais efetivos entre profissionais de saúde e pacientes.

Palavras-chave: Cirurgia de histerectomia, Enfrentamento, Intervenção psicossocial.
\end{abstract}

Hysterectomy: psychosocial aspects and processes of coping

\begin{abstract}
The aim of this study was to investigate psychosocial aspect and constructs of coping with hysterectomy. This is a cohort, longitudinal study, involving 10 women, mean age 44 years, low education and income, attending a municipal hospital in the state of Paraiba. A Mode of Coping Scale (EMEP) and semi-structured interviews conducted in the maternity ward and at home were used, in the interval between the preoperative and at six months post-operative. To analyze the results, descriptive and bivaried statistics and content analysis technique were used. The results showed variability in coping strategies, predominantly in the search for religious practices, followed by problem-focused. The speeches show concern for the loss of femininity and mobilization of feelings of fear about the surgery. The results assist in psychological intervention, stressing more effective communication processes between health professionals and patients.

Keywords: Hysterectomy surgery, Coping behavior, Psychosocial intervention.
\end{abstract}

A histerectomia é uma cirurgia de retirada do útero em consequência de algumas patologias. É uma das cirurgias femininas mais realizadas nos países ocidentais e afeta, atualmente, mais de 107.000 mulheres no Brasil. As causas mais frequentes para realização da histerectomia são benignas, como os miomas (tumores benignos mais comuns no trato reprodutivo), responsáveis por 59,5\% das cirurgias, e causas malignas, como é o caso de cânceres uterinos, em menor percentual (Corleta, Chaves, Krause \& Cappe, 2007).

Alguns estudos sobre essa temática têm constatado que a histerectomia é experimentada por algumas mulheres como golpe no território do prazer, desencadeando mudanças nos padrões sexuais após a cirurgia (Goetsch, 2005; Salvador, Vargens \& Progianti, 2008; Tozo \& cols., 2009). Isso se deve também porque o útero, além da função biológica, tem sua relação com o conceito de feminilidade, por relacionarse ao papel reprodutor da mulher e a sua vida sexual.

A remoção dessa parte essencial do corpo feminino reflete em consequências como a perda da possibilidade de reprodução e parada do ciclo

${ }^{1}$ Endereço para correspondência:

Rua Golfo de Sirte, 51, apt. 504 - Bairro Intermares -

58310-000 - Cabedelo-Paraíba.

E-mail: luciarobertta@yahoo.com.br menstrual, o que não representa prejuízo na saúde física da mulher. De acordo com Saldanha (2003), modificações na estrutura biopsíquica da mulher pode acarretar consequências psicossociais, como a perda da feminilidade, uma vez que o útero historicamente tem sido associado à identidade feminina, ressaltando os aspectos da sexualidade e a função da maternidade. Sendo assim, a necessidade de realizar uma cirurgia para retirada do útero pode produzir inúmeras emoções conflitivas e traumáticas, de insegurança e ansiedade, além dos medos que tradicionalmente uma cirurgia pode despertar nas pessoas (Sbroggio, Osis \& Bedone, 2005; Sebastiani \& Maia, 2005).

Tratando-se da evolução histórica, homens e mulheres desenvolveram-se a partir de contextos próprios, pertencentes ao momento vivido em cada sociedade, quase sempre ditada por homens, onde as atividades das mulheres eram menos valorizadas. Segundo Priore (1999), os conceitos de feminilidade dão relevância ao papel reprodutor da mulher na sua esfera privada, desde anos a.C., resumindo sua existência na maternidade e nas características biológicas principalmente, a presença do útero caracterizava-na como um mal na terra ou como uma santidade. Corroborando essa ideia, Novoa (1991) afirma que a identidade feminina associada ao útero parte desse ponto histórico, resumindo a razão da sua existência na maternidade, onde a retirada do útero 
poderia refletir na incapacidade sexual de sentir prazer. Nesse sentido, Urrutia e Araya (2005) pesquisaram, no Chile, 104 mulheres sobre as características da sexualidade de pacientes histerectomizadas três meses após a cirurgia e verificaram que a maioria das mulheres referiu mudanças na sua vida sexual, considerada positiva.

O construto enfrentamento (coping), segundo Lazarus e Folkman (1984), é um conjunto de esforços mobilizados pelo indivíduo para lidar com situações internas e externas consideradas ameaçadoras/estressoras para sua integridade e bemestar geral e tem sido cada vez mais estudado nas áreas de saúde e humanidades (Santos, 2008). Partindo desses pressupostos, este estudo teve como objetivo investigar aspectos psicossociais e construções de enfrentamento de mulheres submetidas à cirurgia de histerectomia.

\section{Método}

Trata-se de um estudo de coorte, longitudinal, com abordagem quantitativa e qualitativa, realizado no Hospital e Maternidade Padre Alfredo Barbosa (HMPAB), na cidade de Cabedelo (Paraíba), no intervalo entre o pré-cirúrgico e sexto mês do pósoperatório.

\section{Participantes}

Participaram deste estudo 10 mulheres, adultas, internas na clínica cirúrgica do referido hospital. Como critério de inclusão da amostra, utilizou-se: indicação cirúrgica de histerectomia (HTM) total ou parcial, faixa etária de 35 a 65 anos, além da concordância de participação na pesquisa após o conhecimento dos objetivos e procedimentos, da garantia do anonimato e confidencialidade dos dados. Como critério de exclusão, utilizou-se: ter intercorrência psiquiátrica e ter diagnóstico de câncer.

Tinham, em média, 46 anos e 7 meses $(\mathrm{DP}=6,5)$, variando de 41 a 61 anos; eram casadas, com ensino fundamental incompleto, intitulavam-se donas de casa e apenas uma tinha como atividade a pesca de mariscos. A renda familiar declarada varia entre menos de um salário mínimo $(\mathrm{N}=7)$ a 1 salário mínimo $(\mathrm{N}=3)$. Tinham em média 4 filhos (DP=1,05), variando de 3 a 6. A maioria professou a fé católica, com exceção de uma evangélica, mas apenas 3 afirmaram ser praticantes.

\section{Instrumentos}

Utilizou-se a Escala Modos de Enfrentamento de Problemas (EMEP), adaptada e validada para o português por Gimenes e Queiroz (1997). A EMEP contém 45 itens, distribuídos em quatro fatores: enfrentamento focalizado no problema (18 itens, $\alpha=0,84)$; enfrentamento focalizado na emoção (15 itens, $\alpha=0,81$ ); busca de práticas religiosas ( 7 itens, $\alpha=0,74)$ e busca de suporte social ( 5 itens, $\alpha=0,70$ ). As respostas são dadas em escala Likert de cinco pontos (1=Eu nunca faço isso; $5=\mathrm{Eu}$ faço isso sempre).

Ao fim da aplicação dos 45 itens da escala, utilizou-se também uma entrevista semiestruturada, caracterizada pela combinação de perguntas abertas e fechadas a partir dos seguintes eixos temáticos: (1) descoberta da doença, (2) reabilitação e enfrentamento, (3) relacionamentos interpessoais, (4) autoimagem e (5) percepções sobre a vida e expectativas para o futuro. A segunda entrevista (pós-operatório) partiu de duas questões norteadoras (Como está sua vida hoje?; O que mudou após a histerectomia?), visando à avaliação das consequências da cirurgia na vida das pacientes.

\section{Procedimentos}

Inicialmente, foi solicitada autorização ao Comitê de Ética e Pesquisa do Centro de Ciências da Saúde da Universidade Federal da Paraíba, seguido de apresentação e autorização da diretoria do hospital onde os participantes foram pesquisados mediante autorização assinada, aplicação dos instrumentos e aviso de caráter voluntário.

Os instrumentos foram validados e, após verificação de efetividade, a coleta de dados foi realizada em dois momentos: no pré-operatório, com submissão da Escala de Modos de Enfrentamento de Problemas (EMEP) e, em seguida, a entrevista semiestruturada, e transcorridos seis meses após a cirurgia, realizou-se nova entrevista visando à confirmação ou refutação das vivências da cirurgia.

Essa aplicação foi realizada de forma individual, sem tempo determinado, na sala do serviço de psicologia. Para a determinação do número de entrevistas, foi adotado o critério de saturação, que, na concepção de Sá (1998), refere-se à equivalência entre a representação advinda de certo número de indivíduos e um maior número destes.

\section{Análise dos Dados}

Para os dados quantitativos, foram utilizadas análises estatísticas descritivas, com o uso de medidas de posição (média, mediana) e de variabilidade (desvio padrão, amplitude) e a realização de teste bivariado (correlação de Pearson) para verificação de associações entre as variáveis do estudo. Os discursos emergentes nas entrevistas foram analisados quanto aos temas, categorias e subcategorias identificados, com base em recursos metodológicos sugeridos por Bardin (1979) para análise de conteúdo. 


\section{Resultados e Discussões}

De acordo com os dados sociodemográficos das entrevistas, evidenciou-se que as mulheres estavam mais vulneráveis a problemas de saúde, visto terem baixa escolaridade, baixa renda e fazerem pouco uso de serviços de saúde. Também evidenciou-se que $60 \%$ das mulheres já haviam realizado algum tipo de cirurgia e tinham algum conhecimento sobre a histerectomia, o que pode influenciar no modo de enfrentamento à cirurgia que vai realizar (Peniche, 2005).

O tempo médio de diagnóstico foi de 1 ano e 5 meses ( $\mathrm{DP}=0,52)$, variando de 3 meses a 2 anos. Dentre as participantes, 6 afirmaram já terem se submetido a outra cirurgia, em sua maioria ginecológica, e a maioria, dizia conhecer outra pessoa que já se submeteu à cirurgia de histerectomia. A causa das cirurgias de todas as participantes foi miomatoses uterinas, submetendo-se a histerectomias totais e por via abdominal, corroborando a literatura (Halbe, 1993).

De acordo com a EMEP, as formas de lidar com os problemas são diferentes de sujeito a sujeito e, no presente estudo, observou-se que a modalidade de enfrentamento mais usada foi busca de práticas religiosas/pensamento fantasioso, seguida de enfrentamento focalizado no problema. Estratégias focalizadas na busca de suporte social e na emoção foram relatadas em menor frequência no conjunto da amostra estudada, como pode ser visto na Tabela 1.

Tabela 1. Análises descritivas das estratégias de enfrentamento medidas pela EMEP

\begin{tabular}{llll}
\hline \multicolumn{1}{c}{ Fatores } & Média & DP & Amplitude \\
\hline Focalizado no problema & 3,33 & 0,51 & $2,22-3,94$ \\
Focalizado na emoção & 2,24 & 0,57 & $1,67-3,40$ \\
Religioso/Fantasioso & 3,75 & 0,43 & $3,29-4,57$ \\
Busca de suporte social & 2,52 & 1,04 & $1,20-4,20$ \\
\hline
\end{tabular}

A constatação de que as participantes deste estudo utilizaram mais estratégias de busca religiosa e menos estratégias focalizadas na emoção pode estar associada ao próprio perfil das participantes, no que tange à baixa escolaridade e à condição socioeconômica de gênero, fator esse também evidenciado em estudo realizado por Seidl, Tróccoli e Zannon (2001) observando que mulheres com baixa escolaridade apresentaram médias mais elevadas na busca de práticas religiosas como enfrentamento a situações de enfrentamento a problemas de saúde.

Os coeficientes de correlação de Pearson mostraram a presença de associação negativa significativa entre enfrentamento focado no problema e enfrentamento focado na emoção $(r=-0,73 ; p<0,015)$. Evidenciou-se que os escores elevados no primeiro estiveram associados a escores baixos no segundo, apontando relativa incompatibilidade desses dois tipos de estratégia.

Emergiu, ainda, uma correlação com coeficiente de confiabilidade reduzida entre enfrentamento no problema e busca de práticas religiosas /fantasiosas $(r=0,59 ; p<0,06)$, indícios do uso complementar dessas modalidades de enfrentamento pelos participantes. Não se observou associação significativa entre as demais modalidades de enfrentamento.

Com base nos materiais coletados pelas entrevistas no pré-operatório resultaram duas classes temáticas (cirurgia e significados), as quais resultaram em quatro categorias empíricas e onze sub-categorias, conforme pode ser observado na Figura 1.

$\mathrm{Na}$ classe temática cirurgia, categoria Aspectos Clínicos, emergiu a subcategoria Informações sobre a cirurgia que diz respeito à presença ou ausência de informações sobre a doença e a cirurgia. Informações sobre o pré-operatório e esclarecimentos de dúvidas para os pacientes cirúrgicos nessa fase são importantes, mas devem ser manifestadas de forma que o paciente possa interagir e participar (Peniche, 2005; Salimena \& Souza, 2008).

doutor disse que en tinha mioma e tinha que fazer uma cirurgia. Ai en to aqui [...] mas en queria sabe mais da cirurgia, já pensou, era bom [...] se en sabesse de alguma coisa a mais eu ia ficar mais calma, não sei de nada. (p. 3)

Quanto aos "sintomas", as participantes verbalizavam os mais frequentes, correspondendo com a literatura que afirmam que os sintomas mais frequentes são hemorragias e dores pélvicas crônicas, dentre outros (Halbe, 1993). E referente a "diagnóstico" evidenciou-se o enfrentamento diante de exames e do diagnóstico, demonstrando a relação entre a transmissão do diagnóstico/necessidade de cirurgia com implicações psicológicas, físicas e sociais. 


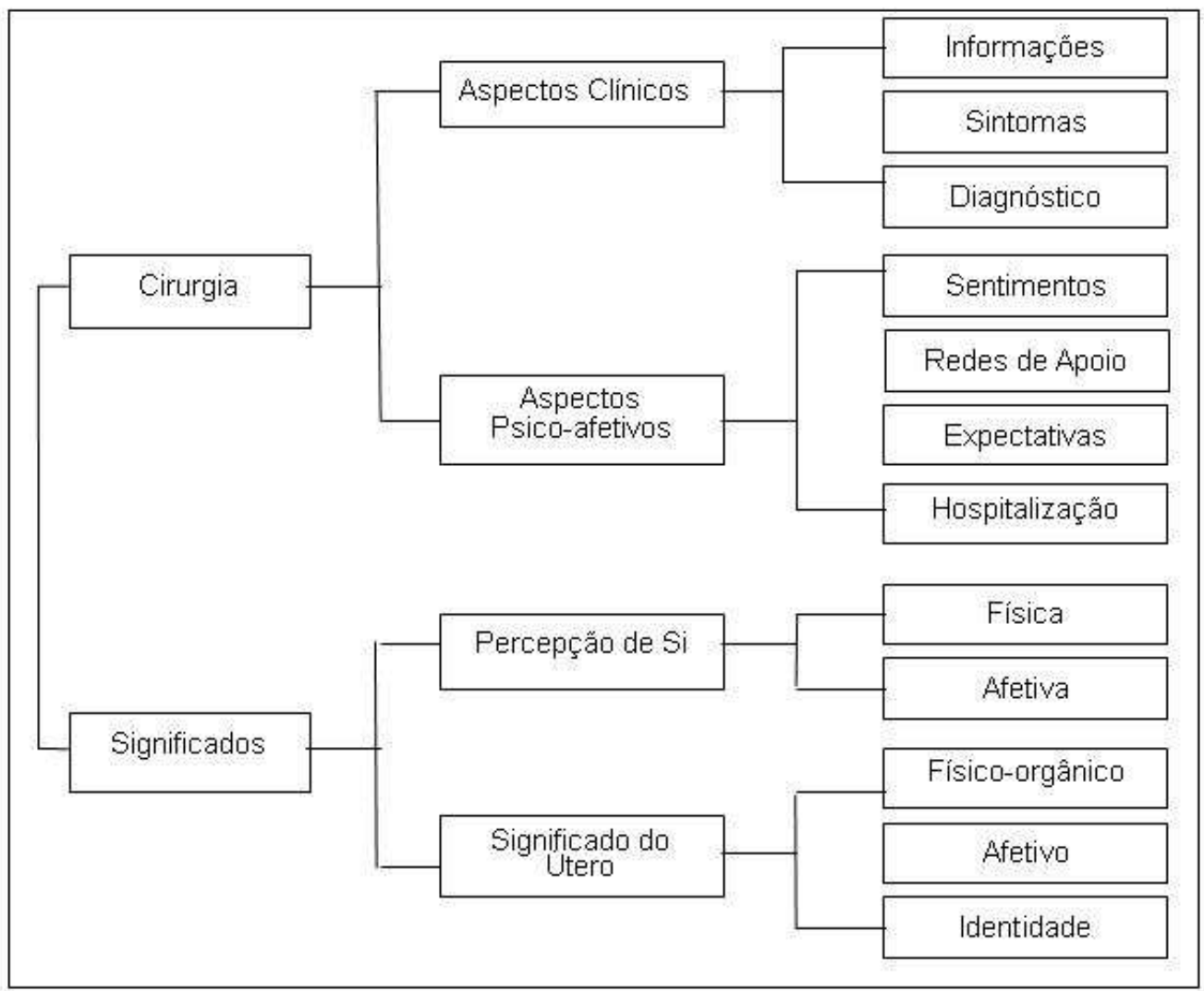

Figura 1. Classes, categorias e subcategorias emergentes da entrevista no pré-operatório

...eu tenho essas dores, sabe, faz. um tempo, mas tem uns seis meses que vem piorando, é um caso sério [...] chego a pensar que meu sangue vai acabar. (p. 2)

Desde não sei quando que os médicos me disseram que eu tinha mioma, mas eu não cuidei, fui deixando, deixando, a te que tô aqui hoje [...] eu não me cuidei. (p. 7)

Outra categoria emergente foi Aspectos psicoafetivos com a subcategoria "sentimentos quanto à cirurgia", referentes à preocupação, o medo diante da anestesia, enquanto uma reação emocional real, à ansiedade em relação ao procedimento cirúrgico em si, ou mesmo aos processos de hospitalização (Leon, 2007).

... a gente fica um pouco tensa, pensando como vai ser [...] eu só tenho medo da aplicação da anestesia, da furada.....(fez silêncio)... anestesia é coisa perigosa. (p.

8)

A partir da subcategoria "rede de apoio", evidenciou-se que as participantes mostraram que se sentiam mais apoiadas pelos filhos do que pelos companheiros e na subcategoria "expectativa", foi predominante o aspecto positivo, respectivamente. $\mathrm{Na}$ subcategoria de "rede de apoio", evidenciou-se que as participantes sentiam-se mais apoiadas pelos filhos e esposos, mas algumas delas demonstravam também necessidade de seus companheiros, embora sentissem temor quanto à infidelidade dos maridos após a cirurgia.

... É, eu tenho pensado nos meus filhos, minha casa, meu marido [...] no geral todo mundo me apóia. (p. 8)

Em relação à subcategoria "hospitalização", evidenciaram-se experiências ulteriores e as percepções que têm do processo de hospitalização, esta que é um momento difícil na vida de uma pessoa, alterando seus estados emocionais, com rupturas de cotidiano, deixando seus lares e trabalhos, enfim, modifica toda uma estrutura antes estável, dando lugar ao inesperado (Cury, 2000).

...é muito ruim ficar no hospital, viu? É um lugar de muito sofrimento, umas pessoas ficam boas logo, outras não, olhe é muito triste. (p. 5)

$\mathrm{Na}$ classe temática significados, categoria Percepção de si, verificaram-se os aspectos "físico" e "afetivo" Kebbe (2006) pensa a imagem corporal como a figuração que a pessoa tem do seu corpo, seja em termo de aparência física, seja em funcionalidade, enfim, é representativo da subjetividade da pessoa e da experiência individual com seu universo. E a categoria Significado do útero dividiu-se em três sub-categorias, denominadas "físico-orgânico", para representar as verbalizações concernentes às concepções do útero, categoria "afetivo", para os aspectos afetivos e 
"construção de identidade", que remontam à relação do útero com a identidade feminina.

....sou um pedaço de carne cortada [...] gorda, pobre, não tenho nada. (p. 6)

...Para mim, útero é uma coisa de mulher, significa que sou mulher. (p. 2)
Já com base nas entrevistas realizadas no pósoperatório, após seis meses da cirurgia, permitiram a construção de 3 classes temáticas, 5 categorias e 3 subcategorias, conforme observado na Figura 2.

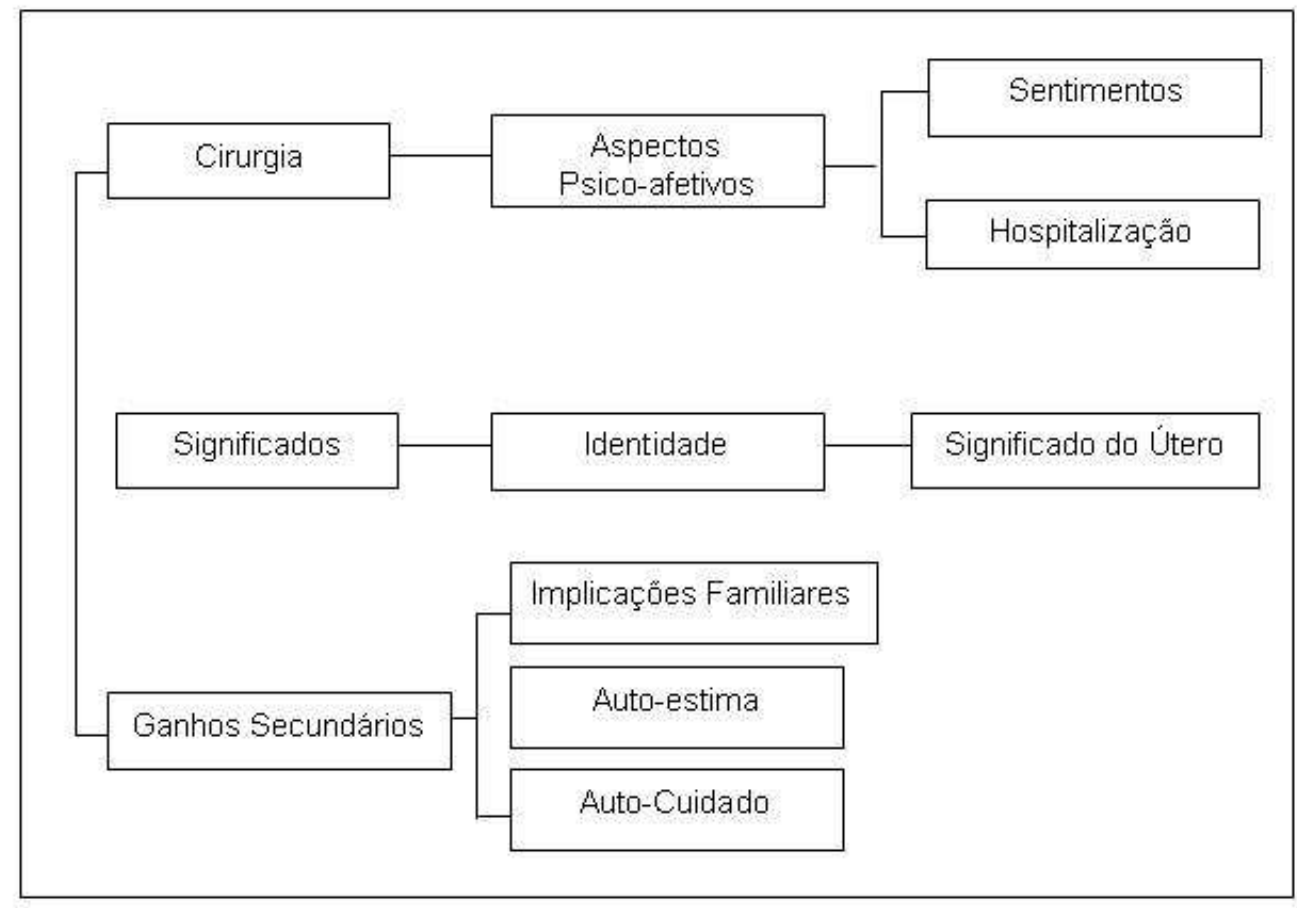

Figura 2. Classes, categorias e subcategorias emergentes da entrevista no pós-operatório

$\mathrm{Na}$ classe temática cirurgia, categoria Aspectos psico-afetivos, emergiu a subcategoria "sentimentos", situando a cirurgia realizada como lembrança de uma experiência vivida, mas também trazendo recordação do medo, da ansiedade e da insegurança, bem como expressões de sentimentos atuais, como a culpa. Havia também um sentimento de satisfação e alívio por ter transcorrido àqueles momentos dolorosos.

só o medo que eu senti foi demais, tinha medo da anestesia, ficava só pensando, da véspera eu nem consegui dormir direito, de tanto pensar. (p. 1)

Satisfeitas com o resultado da cirurgia, as participantes recordaram o sentimento de impotência diante dos imprevistos no momento de pós-operatório. Isso pode ser explicado porque a comunicação entre o médico e a paciente pode ter sido insuficiente após a cirurgia, ficando as mulheres sem informações essenciais para a recuperação.

$\mathrm{Na}$ subcategoria "hospitalização", as participantes enunciaram em seus discursos suas experiências quanto ao processo de hospitalização, como perceberam a hospitalização e como foram tratadas segundo a experiência vivenciada há 6 meses. Grande parte dos discursos versou sobre a própria questão da ambientação hospitalar, enquanto lugares tristes, causadores de solidão, cheios de doenças, onde as pessoas eram "estranhas" e onde os profissionais causavam impacto por conta da vestimenta branca.

ah você sabe, hospital tem aquele negócio de ter medo, né, de tristeza, tudo é tão ruim, todo mundo é estranho [...] que tudo é brancão, todo mundo. (p. 4)

Por meio da classe temática significado evidenciou-se uma categoria de Identidade, tratando da significação do útero e foi verificado que as mulheres sentiam-se "normais", sem alterações pela retirada do útero, ou mesmo melhores do que antes da cirurgia.

Olhe que ele não tem reclamado. Assim, das zueiras nossas, aquelas das noitinhas, en que pensava que ia ficar daquele jeito, fria, oca. (p. 3)

Enfim, o útero era e continua sendo um órgão de extrema relevância para a mulher e a sua retirada 
causa temores quanto à transformação da feminilidade, temores estes que ficam guardados na memória.

Uma última classe temática emergente foi ganhos secundários, referindo-se a alguns ganhos que as mulheres obtiveram com todo o processo de hospitalização, tratamento e recuperação da cirurgia de histerectomia, principalmente no que tange às questões de atenção familiar e atenção para si. São relativamente frequentes os casos de pessoas que, em função de seus problemas de saúde, passam a deter um enorme poder no interior das relações familiares, mantendo com isso muitos privilégios pessoais.

A categoria Implicaşões familiares retrata alguns ganhos secundários que as participantes tiveram, relacionados no relacionamento familiar, estando esta categoria presente nos discursos de quase toda amostra.

Sabe-se que uma cirurgia implica momentos de mudanças que por vezes são abruptas e inesperadas e que afeta não somente os pacientes, mas todos os que participam do contexto familiar do paciente, tendo esta família um papel importante para suportar as dificuldades transmitidas pela doença e para lidar melhor com o tratamento e a recuperação. Os depoimentos evidenciam que a família desenvolve um papel fundamental no processo de recuperação do paciente, criando mecanismos de união e força entre seus integrantes, inclusive dos companheiros.

A sorte é que minha familia esteve sempre do men lado, familia é a melhor coisa do mundo viu. (p. 1)

A participação efetiva e afetiva de companheiros de mulheres em tratamento de saúde em nível cirúrgico, segundo Biffi (2003), possibilita uma recuperação em condições melhores e mais saudáveis e cujo suporte do parceiro sexual demonstra que este se reconhece como elemento de apoio e afeto. Ampliando esses apoios, pode-se observar que representantes da extensão familiar, como amigos e vizinhos, também foram considerados importantes.

$\mathrm{Na}$ categoria Autocuidado, definido como o cuidado desenvolvido pelo indivíduo em benefício próprio, evidenciou-se que as mulheres histerectomizadas passaram a cuidar-se mais, momento através do qual elas fizeram uma análise sobre seu posicionamento pessoal diante das situações vivenciadas e buscaram alternativas para melhorar o processo de viver, estimulando na decisão de assumir, a partir de então, novos papéis, responsabilidades e compromissos com si próprias.

Quero continuar cuidando das minhas coisas, minha casinha e agora cuidar também mais da minha saúde. (p. 5)

A categoria Autoestima foi evidenciada, uma vez que foi percebida nas mulheres uma elevação da autoestima, considerada como a avaliação subjectiva que uma pessoa faz de si mesma como positiva ou negativa em algum grau (Nunes \& Cols., 2009; Salimena \& Souza, 2008). Passada a cirurgia, o desejo dessas mulheres histerectomizadas foi de voltar as suas atividaddes normais e deixar de lado as ameaças que lhes causaram temores antes da cirurgia, sentiram necessidade de resgatar a vida social e as questões de saúde.

Nem ficou o corte direito! Eu pensava nisso [...] é porque en estou tão boa que nem ligo para o corte. (p. 3)

Com a cirurgia, essas mulheres puderam experenciar um momento de abalo que proporcionou um processo de crescimento, amadurecimento, tendo o autocuidado como um ganho obtido. Segundo Neves e Wink (2007), esse autocuidado surge como um processo cognitivo, afetivo e comportamental que se consolida quando a pessoa compromete-se em assumir responsabilidade pessoal em direção à conquista de crescimento próprio.

\section{Considerações finais}

Para as participantes desta pesquisa, a histerectomia abala a mulher não somente por ser uma intervenção cirúrgica altamente invasiva, mas por ser um procedimento que leva a crenças de perda da feminilidade em consequência da retirada do útero, que é historicamente representativo do "ser mulher", importante na sexualidade, maternidade e até mesmo na autoestima.

Esse fato pode ser observado no discurso diferenciado dessas mulheres nos dois momentos das entrevistas. No pré-operatório, havia todo um temor e um desespero por parte dessas mulheres na crença de que iriam tornar-se diferentes, mobilizando a feminilidade e temendo a frigidez, o que poderia ter como consequência a perda de seus maridos. Entretanto, essa percepção foi refeita nos discursos do pós-cirúrgico, quando constataram que se sentiam mulher como antes, que todos os medos eram infundados, decorrentes principalmente da falta de conhecimento técnico e clínico sobre as repercussões da histerectomia.

No conjunto dos depoimentos no pré e pósoperatório, pôde-se verificar um leque de percepções, sentimentos e transformações que puderam ser modificados depois da cirurgia, após uma segunda avaliação do enfrentamento. No enfrentamento à situação da cirurgia, os discursos manifestaram sentimentos dos mais variados como medos do câncer, $\mathrm{da}$ anestesia e da morte, insegurança e ansiedade, sentimentos estes que, dependendo do grau de 
intensidade, podem afetar o quadro clínico, com possibilidade da não correspondência dos tratamentos medicamentosos e, se mais grave, como, por exemplo, um processo depressivo, o estabelecimento de um quadro infeccioso.

Com tamanha mobilização que a cirurgia causou para essas mulheres, este estudo mostrou que houve também alguns ganhos secundários, com a obtenção de mais atenção da família e de amigos, aumento da autoestima e uma postura de auto-cuidado, com a conscientização da necessidade de prevenção aos agravos da saúde.

Essas constatações remetem à importância da equipe de saúde tanto na prestação do cuidado clínico como no enfrentamento psicossocial aos agravos, devendo ser baseada em um aspecto primordial nas relações humanas: a comunicação. Especificamente em relação à saúde, tem um valor ampliado porque pode tratar e recuperar vidas, proporcionando a informação necessária para a compreensão da doença, minimização da angústia e alívio da dor. Enfim, este estudo dá visibilidade aos profissionais de saúde para a importância de uma comunicação dirigida com informações quanto à cirurgia, minimizando a dor, alivia dúvidas e auxilia nos enfrentamentos aos eventos estressores.

O que se constata são questões psicossociais e dificuldades que afetam essas mulheres no précirúrgico, inclusive ligadas à sexualidade e que poderiam ser atenuadas com um trabalho focado na atenção pré-cirúrgica, indicando a importância de que a comunicação prevaleça e que atenção humanizada seja valorizada pelas equipes de saúde, em uma perspectiva de ação integral, multi e interdisciplinar, levando a uma ressignificação de suas vidas.

Dessa forma, esta seria também uma das contribuições deste estudo, reforçar a importância das equipes multidisciplinares em hospitais e/ou locais de cuidados de saúde, uma vez que o foco principal no trabalho com pessoas acometidas por uma enfermidade não é a doença em si, mas elas mesmas. É necessário mais que um enfermeiro, um médico, um fisioterapeuta, ou qualquer outro profissional de saúde, mas uma equipe que possa ver em sua frente uma pessoa que está com problemas, que sofre, tem angústias e que quer ser ouvida. Faz-se necessário reforçar a importância do papel do psicólogo, que não só favorece ao paciente a escuta direcionada, mas a compreensão do tratamento e a cooperação na recuperação.

A partir deste estudo, pretende-se subsidiar programas de intervenção psicossocial pré, trans e póscirúrgica, bem como a capacitação de profissionais de saúde no atendimento à mulher. Como uma das limitações deste estudo, aponta-se para os restritos estudos nacionais ligados aos aspectos psicossociais dessa cirurgia, sendo necessário o desenvolvimento e aprofundamento de novas pesquisas que abranjam este universo tão vasto do mundo feminino.

\section{Referências}

Angerami-Camon, V. A (1996). O doente, a psicologia e o hospital. São Paulo: Pioneira.

Bardin, L. (1979). Análise de conteúdo. Lisboa: Edições 70.

Biffi, R. G. (2003). A dinâmica familiar de um grupo de mulheres com câncer de mama. (Tese de doutorado). São Paulo: Universidade de São Paulo - Escola de Enfermagem de Ribeirão Preto.

Chou, C. C., Lee, T. Y., Sun, C. C., Lin, S. S. \& Chen, L. F. (2006). Husband's experiences before wives' histetectomy. Journal of Nursing Research, 14(2), 113122

Corleta, H. E., Chaves, E. B. M., Krause, M. S. \& Cappe, E. (2007). Tratamento atual dos miomas. Revista Brasileira de Ginecologia e Obstetrícia, 29(6), 324-328.

Cury, A. F. (2000). Aspectos emocionais da cirurgia ginecológica. Femina, 28(9), 509-511.

Endler, N. S. \& Parker, J. D. A. (1999). Coping inventory for stressful situations (CISS). Manual ( $2^{\mathrm{a}}$ ed.). Toronto: Multi-Health Systems Inc.

Gimenes, M. M. G. \& Queiroz, B. (1997). As diferentes fases de enfrentamento durante o primeiro ano após a mastectomia. Em M. G. G. Gimenes \& M. H. Fávero (Orgs.). A mulher e o cancer. (pp. 171-195). Campinas: Psy.

Goetsch, M. F (2005). The effect of total hysterectomy on specific sexual sensations. American Journal of Obstet. Gynecol., 192(6),1922-1927.

Halbe, H. W. (1993). Tratado de ginecologia. São Paulo: Roca.

Kebbe, L. M. (2006). Desempenho de atividade e imagem corporal: representações sociais de um grupo de mulheres com câncer de mama. (Tese de doutorado). São Paulo: Universidade de São Paulo - Escola de Enfermagem de Ribeira Preto.

Lazarus, R. S. \& Folkman, S. (1984). Stress, appraisal and coping. Nova Iorque: Springer Publishing Co.

Leon, M. D. (2007). Ansiedade e medo pré-operatório de cirurgia cardíaca: intervenção de enfermagem na abordagem psicossocial. (Dissertação de mestrado). São Paulo: 
Universidade de São Paulo - Escola de Enfermagem.

Neves, E. P. \& Wink, S. (2007). O autocuidado no processo de viver: enfermeiras compartilham concepções e vivências em sua trajetória profissional. Texto \& Contexto - Enfermagem, 16(1), 172-179.

Novoa, A. M. (1991). Histerectomia: efeitos emocionais na identidade feminina. Opinião, 6, 9395.

Nunes, M. P. R. S., Gomes, V. L. O., Padilha, M. I., Gomes, G. C. \& Fonseca, A. D. (2009). Representações de mulheres acerca da histerectomia em seu processo de viver. Escola Anna Nery Revista de Enfermagem, 13(3), 574-581.

Peniche, A. C. G. (2005). A ansiedade e o paciente cirúrgico: Análise das variáveis intervenientes. (Dissertação de Mestrado). São Paulo: Universidade de São Paulo - Escola de Enfermagem.

Priore, M. D. (1999). Viagem pelo imaginário do interior feminino. Revista Brasileira de História, 19(37), 179-194.

Sá, C. P. (1998). A construção do objeto de pesquisa em representacōos sociais. Rio de Janeiro: UERJ.

Saldanha, A. A. W. (2003). Vulnerabilidade e construções de enfrentamento da soropositividade ao HIV por mulheres infectadas em relacionamento estável. (Tese de Doutorado). São Paulo: Universidade de São Paulo - Pós Graduação em Psicologia, Faculdade de Filosofia, Ciências e Letras de Ribeirão Preto.

Salimena, A. M. O. \& Souza, I. E. O. (2008). O sentido da sexualidade de mulheres submetidas à histerectomia: uma contribuição da enfermagem para a integralidade da assistência ginecológica. Escola Anna Nery Revista de Enfermagem, 12(4), 637644.

Salvador, R. T., Vargens, O. M. C. \& Progianti, J. M. (2008). Sexualidade e histerectomia: mitos e realidade. Revista Gaúcha de Enfermagem, 29(2), 320323.

Sobre as autoras:

Lúcia Robertta Matos Silva dos Santos é mestre em Psicologia Social pela UFPB, pesquisadora do Núcleo de Pesquisa Vulnerabilidades e Promoção de Saúde da UFPB, professora da Graduação e da Pós-Graduação das Faculdades Integradas de Patos/PB, chefe do Serviço de Psicologia do Hospital e Maternidade Padre Alfredo Barbosa/PB.

Ana Alayde Werba Saldanha é doutora em Psicologia Social pela Universidade de São Paulo, professora adjunta do Programa de Pós-Graduação em Psicologia Social da Universidade Federal da Paraíba.
Santos, L. R. M. S. (2008). Processos de enfrentamento e repercussões psicossociais em pacientes submetidas a cirurgia de histerectomia. (Dissertação de Mestrado). Paraíba: Universidade Federal da Paraíba - Programa de Pós-Graduação em Psicologia Social.

Sbroggio, A. M. R., Osis, M. J. M. D. \& Bedone, A. J. (2005). O significado da retirada do útero para as mulheres: um estudo qualitativo. Revista da Associação Médica Brasileira, 51(5), 270-274.

Sebastiani, R. W. \& Maia, E. M. C. (2005). Contribuições da psicologia da saúde hospitalar na atenção ao paciente cirúrgico. Acta Cirúrgica Brasileira, 20(1), 50-55.

Seidl, E. M. F. (2005). Enfrentamento, aspectos clínicos e sociodemográficos de pessoas vivendo com HIV/AIDS. Estudos de Psicologia, 10(3), 421429 .

Seidl, E. M. F., Tróccoli, B. T. \& Zannon, C. M. L. C. (2001). Análise fatorial de uma medida de estratégias de enfrentamento. Psicologia: Teoria $e$ Pesquisa, 17(3), 225-234.

Tozo, I. M., Moraes, J. C., Lima, S. M. R., Golçalves, N., Auge, A. P. F., Rossi, L. M. \& Aoki, T. (2009). Avaliação da sexualidade em mulheres submetidas à histerectomia para tratamento do leiomioma uterino. Revista Brasileira de Ginecologia e Obstetrícia, 31(10), 503-507.

Urrutia, M. T. \& Araya, A. A. (2005). Sexualidad em mujeres histerectomizadas al tecer mês posterior a la cirugía. Revista Chilena de Obstetricia y Ginecologia, 70(3), 160-165.
Recebido em 04/11/2010
Reformulado em 12/04/2011
Aprovado em 22/06/2011 